ARAŞTIRMA MAKALESI

\author{
Agah Bahadır Öztürk ${ }^{1}$ \\ Bilge Sönmez ${ }^{2}$
}

\begin{abstract}
${ }^{1}$ Adıyaman Üniversitesi Tıp Fakültesi Aile Hekimliği ABD

${ }^{2}$ Aile Hekimliği Uzmanı, Ankara Halk Sağlığı Müdürlüğü, Batıkent 6 Nolu Aile Sağlığı Merkezi, Ankara
\end{abstract}

\section{Yazış̧ma Adresi:}

Uz.Dr.Bilge Sönmez

Aile Hekimliği Uzmanı, Ankara Halk Sağllı̆g Müdürlügü, Batıkent 6 Nolu Aile Sağllğı Merkezi, Ankara

E-mail:bilgesnmez@yahoo.com

\section{Konuralp Tıp Dergisi}

e-ISSN1309-3878

konuralptipdergi@duzce.edu.tr konuralptipdergisi@gmail.com www.konuralptipdergi.duzce.edu.tr

\section{Güneydoğu Anadolu Kursalında Yaşayan Çocuklarda Ağız ve Diş Sağlığı Değerlendirilmesi: Kesitsel Saha Çalışması Sonuçları \\ ÖZET}

Giriş ve Amaç; Ağız ve diş hastalıkları dünyada ve ülkemizde hala önemli bir sağlık sorunudur. Bu çalışmanın amacı, Adıyaman Çelikhan ilçesi ve bağlı köylerinde yaşayan 4-15 yaş arası öğrencilerde diş çürüğü profilini ortaya koyan DMFT ( $\mathrm{D}=$ Çürük, M=Eksik, F=Dolgulu diş) İndeksini belirleyerek ağızdiş sağlı̆̆ı durumlarını ve etkileyen faktörleri tespit etmektir.

Materyal Metod; Tanımlayıcı nitelikteki bu çalışma 15 Mayıs - 15 Haziran 2015 tarihleri arasında Adıyaman Çelikhan İlçesi Milli Eğitim Müdürlüğüne bağlı bulunan 2 anaokul, 12 köy ve 5 merkez ilkokulu, 2 köy ve 5 merkez ortaokulunda bulunan 4-15 yaş aralığındaki 2358 öğrenci üzerinde yapılmıştır. Her bir öğrencinin genel çürük deneyimi klinik ve radyografik bulgular baz alınarak DSÖ’nün geliştirdiği DMFT indeksine göre belirlenmiştir.

Bulgular; Çalışmada 4-15 yaş arası toplam 2358 öğrencinin verileri analiz edilmiştir. Çalışmaya katılan 2358 çocuktan, 2218'inde diş çürüğü saptanmıştır. 5 yaş grubu çocukların DMFT indeksi ortalama 3,07 (n=26) iken 12 yaş dmft indeksi ortalama 2,83 $(n=323) 15$ yaş dmtf indeksi ortalama 3,24 $(n=34)$ olarak hesaplanmıştır. Yaş grupları arasında DMFT değerleri arasında istatistiksel olarak anlamlı farklılık bulunmamıştır ( $\mathrm{p}>0,05)$.

Sonuç; Adıyaman ili kırsalında yaşayan çocuklarda tespit edilen çürük diş oranı ve DMFT indeksi ülke genelindeki 1.9 değerine göre yüksek olup DSÖ' nün 21. yüzyıl için hedefi olan 1.5 değerinden de çok uzaktadır. Koruyucu önlemlerle birlikte yapılan tedavi hizmetlerinin eğitim programları ile desteklenerek çocuklara yönelik yaygınlaştırılması ülkemizde çürük prevalansının azalmasına katkı sağlayacaktır.

Anahtar Kelimeler: Tarama, Diş Sağlığı, çocuklar

\section{Assessment of Oral and Dental Health in Children Living in Southeast Anatolia Rural: Cross-Sectional Field Results \\ ABSTRACT}

Introduction and Aim: Oral and tooth diseases ara major concern in our country and the world.The aim of this survey is determining DMTF (decayed, missing, and filled teeth) indexes profile of Adiyaman Çelikhan village in children of ages 4 to 15 and conditions affecting oral and tooth health. Materyal Metod; This descriptive survey is performed in 2 preschool, 12 village 5 town center primary schools, 2 village and 5 town center secondary schools among 4 to 15 years of aged with a total number of 2358 students between May 15 and June 15 ,2015. Tooth experience of every child described by indexes of DMTF which is developed by clinical and radiografic findings. Results: Datas of students aged between 4 to 15 with a total number of 2358 were analysed. Mean DMFT index was $3.07(n=26)$ in 5 years old children and 2,83 $(n=323)$ in 12 years old children, and $3.24(n=34)$ in 15 years old children. There was no statistically significant difference between DMFT indexes of different ages (p>0,05). Conclusion: Described tooth decay rate and DMFT index in rural parts of Adiyaman is high compared to country's mean index of 1,9 and far high from the target of WHO's 21th century target index of 1.5 . Treatment services utilized with preventive precautions need to be supported with education programs and performed prevelant among children, would decrease prevelance of tooth decay in our country.

Keywords: Survey, Dental Health, Children 


\section{GİRIS}

Sağlıklı ve kaliteli bir yaşam için ağız ve diş sağlığını korumanın önemi büyüktür. Her yaş grubunda görülebilen ağız ve diş hastalıklarının prevalansı, toplumların yaşam biçimi ve beslenme alışkanlıklarına bağlı olarak değişkenlik göstermektedir. Diş çürükleri ve periodontal hastalıklar toplumda ağız ve diş sağlığını en çok etkileyen problemlerdir. Gelişmiş ülkelerde diş çürüğü prevelansı, yüksek sosyoekonomik düzey, etkin ve yaygın diş hekimliği hizmetleri ile kişisel hijyen uygulama bilincinin artışı sonucunda hızla düşmektedir (1). Gelişmekte olan ülkelerde ise düşük sosyo-ekonomik düzey, bol miktarda şekerli gida tüketme, yetersiz kalsiyum, flor ve D vitamini alımı gibi çürük oluşma olasılığını artıran diyet alışkanlığı, fokal enfeksiyonlar, yetersiz oral hijyen, yetersiz korunma ve bakım hizmetleri gibi faktörler nedeniyle artmaktadır (2,3). Gelişmekte olan ülkeler grubuna dahil edilen ülkemizde de ağız ve diş hastalıkları çocukluk çağından itibaren yüksek oranda görülmektedir (4).

Diş çürüğü, karyojenik mikroorganizmaların besin maddelerini fermente etmesiyle oluşan asitlerin, plak aracılığı ile diş dokularının harabiyetine neden olduğu bir dizi histoşimik yıkılma olayıdır (5). Çürük oluşumunda bireyin yaşı, cinsiyeti, tükürük miktarı, sosyoekonomik durumu , beslenme ve ağız bakım alışkanlıkları, immunolojik ve sistemik faktörler gibi birçok belirleyici unsur vardır $(4,6,7)$. Gereken önem verilmediği için tedavi edilmeyen diş çürükleri yalnızca tıbbi değil aynı zamanda, sosyal ve ekonomik açıdan da ciddi sorunlara neden olabilir. Özellikle çocukluk döneminde diş çürükleri ağrı, enfeksiyon ve diş kaybının yanı sıra beslenme bozukluğu, büyüme ve gelişme problemleri, gelecekte ortodontik düzeltme gereksinimi olabilecek estetik problemler, konuşma bozukluğu, özgüven kaybı ve okul başarısında düşme gibi bir dizi olumsuz sonuçlar doğurabilir (8). $\mathrm{Bu}$ nedenle çocukluk yaş grubunda düzenli periyodik diş muayeneleri yapılması ileride oluşabilecek bu problemlerin önüne geçilmesi açısından önemlidir(9).

Ağız ve diş sağlığı hizmetleri gelişmekte olan ülkelerde yeterli ve etkin değildir. Diş ve dişeti hastalıkları, önlenebilir hastalıklar grubuna girmesine rağmen (10), diş çürüğü geleneksel sağlık uygulamalarında genellikle oluştuktan sonra tedavi edilmektedir. Bu uygulama çürüğe neden olan faktörleri ortadan kaldırmadığı için yeni çürük oluşumuna zemin hazırlamaktadır. Oysa koruyucu önlemlerle birlikte tedavi edici uygulamaların beraber yapıldığı modern sağlık uygulamaları, etiyolojik faktörleri de göz önünde bulundurduğu için, bireylerin ağı ve diş sağlığı düzeyini geliştirerek yeni çürük oluşumu engellemesine dayalıdır (11). Ağız ve diş sağlığı sorunlarına yönelik koruyucu ve tedavi edici hizmetlerin doğru planlanabilmesi ve yaşam kalitesinin artırılabilmesi için öncelikle toplumun ve bireylerin ağız diş sağlığı profilinin doğru ortaya konması gerekmektedir. Ülke çapında ağız ve diş sağlığı düzeyini belirlemeye yönelik sınırlı sayıda araştırma mevcuttur.

Bu çalışmanın amacı, Güneydoğuanadolu kırsalında yaşayan 4 ila 15 yaş grubu öğrencilerde diş çürüğü profilini ortaya koyan DMFT (Çürük Kayıp-Dolgulu Diş) İndeksini belirleyerek ağız ve diş sağlığı durumlarını ve etkileyen faktörleri tespit etmektir.

\section{YÖNTEM}

Çalışma tanımlayıcı nitelikte olup, 15 Mayıs ila 15 Haziran 2015 tarihleri arasında Adıyaman il merkezine 56 km uzaklıktaki Çelikhan İlçe Milli Eğitim Müdürlüğü'ne bağlı anaokul ve ilköğretim okullarında öğrenim görmekte olan 4 ila 15 yaş aralığındaki öğrenciler üzerinde yapılmıştır. Hedef kitlemiz olan iki anaokul, 14 köy ve 10 merkez ilköğretim okulunda bulunan 2620 öğrenciden çalışmanın yapıldığı tarihlerde devamsızlık nedeniyle okulda bulunmayan ve çalışmaya katılmayı kabul etmeyen 262'si çalışma dışı bırakılmıştır. Çalışmada, toplam 2358 öğrencinin sonuçları değerlendirilmiştir.

Çalışmaya dahil edilen tüm öğrencilerin ebebeynlerinden, yapılacak muayene ve tıbbi uygulamalar için bilgilendirme sonrası yazılı onam alınmıştır. Öğrencilere veliler ve/veya öğretmenler denetiminde araştırmacı tarafından daha önceden yapılmış epidemiyolojik çalışmalardan yararlanılarak hazırlanan, çalışmaya katılanların sosyodemografik özellikleri ve ağı sağlığı konusundaki tutum ve davranışlarına yönelik soruları içeren bir anket formu uygulanmıştır. Tüm öğrenciler okul ortamında diş sağlığı ekibindeki bir diş hekimi tarafından ünit 1şı̆̆ı, ağız aynası ve sonda yardımıyla, Dünya Sağlık Örgütü (DSÖ) teşhis önerilerine göre (12) klinik olarak muayene edilmiş, çürük teşhisleri konulmuş, koruyucu ve erken önleyici tedaviler kapsamında tıbbi mudahaleleri yapılmıştır.

Çalışmada, ara yüz çürüklerinin kesin tanısı için diş hekimi tarafından gerekli görülen öğrencilere portatif digital görüntüleme yöntemi (RVG) kullanılmıştır. İhtiyaç duyulan bazı hastalar için, planlanan tedavi süreçlerinde onamlar alındıktana sonra panoramik dijital görüntüleme yöntemi kullanılmıştır. Muayene ve tetkik sonuçları bilgisayar ortamında kayıt altınaalınmıştır.

Her öğrencinin genel çürük deneyimi klinik ve radyografik bulgular baz alınarak DSÖ’nün geliştirdiği DMFT ( $\mathrm{D}=$ Çürük, M=Eksik, $\mathrm{F}=$ Dolgulu) indeksine göre belirlenmiştir. Çalışmanın yürütülebilmesi için çalışma öncesinde Adıyaman Valiliği ve İl Milli Eğitim Müdürlüğünden gerekli izinler alınmıştır. 


\section{İSTATISTIKSEL ANALIZ}

Verilerin istatistiksel analizinde SPSS 16.0 programı kullanılmıştır. Çalışma verileri yüzde olarak analiz edilerek verilmiş bazı iki değişkenli analizlerde istatistiksel anlamlılığı değerlendirmek için ki-kare testi uygulanmıştır. İstatistiksel anlamlılık düzeyi $\mathrm{p}<0,05$ olarak kabul edilmiştir.

\section{BULGULAR}

Çalışmada Adıyaman ili Çelikhan İlçesi Milli Eğitim Müdürlüğü’ne bağlı bulunan iki anaokul, 17 ilkokul ve yedi ortaokulda okuyan 4 ila 15 yaş arası 2358 öğrencinin anket ve muayene sonuçları değerlendirilmiştir.

Çalışmaya dahil edilen öğrencilerin \%50,5 'i kız \%49,4'ü erkektir (Tablo 1).

Tablo 1. Araştırma kapsamında muayene edilen öğrencilerin yaş gruplarına ve

cinsiyete göre dağılımı

\begin{tabular}{|c|c|c|c|}
\hline Yaş & $\begin{array}{c}\text { Erkek Çocuk } \\
\mathbf{n ( \% )}\end{array}$ & $\begin{array}{c}\text { Kiz Çocuk } \\
\mathbf{n}(\mathbf{\%})\end{array}$ & $\begin{array}{c}\text { Toplam Çocuk } \\
\mathbf{n}(\mathbf{\%})\end{array}$ \\
\hline $\mathbf{4}$ & $6(0,25)$ & $2(0,08)$ & $8(0,3)$ \\
\hline $\mathbf{5}$ & $13(0,55)$ & $13(0,55)$ & $26(1,1)$ \\
\hline $\mathbf{6}$ & $34(1,4)$ & $34(1,4)$ & $68(2,8)$ \\
\hline $\mathbf{7}$ & $159(6,7)$ & $151(6,4)$ & $310(13,1)$ \\
\hline $\mathbf{8}$ & $98(4,2)$ & $114(4,7)$ & $212(8,9)$ \\
\hline $\mathbf{9}$ & $115(4,9)$ & $122(5,1)$ & $237(10)$ \\
\hline $\mathbf{1 0}$ & $133(5,6)$ & $155(6,6)$ & $288(12,2)$ \\
\hline $\mathbf{1 1}$ & $143(6,1)$ & $152(6,4)$ & $295(12,5)$ \\
\hline $\mathbf{1 2}$ & $168(7,1)$ & $155(6,5)$ & $323(13,6)$ \\
\hline $\mathbf{1 3}$ & $150(6,3)$ & $140(5,9)$ & $290(12,2)$ \\
\hline $\mathbf{1 4}$ & $126(5,3)$ & $141(6)$ & $34(1,4)$ \\
\hline $\mathbf{1 5}$ & $20(0,8)$ & $14(0,6)$ & $2358(100)$ \\
\hline Toplam & $1165(49,4)$ & $1193(50,5)$ & \\
\hline
\end{tabular}

Öğrencilerin \%89,4’ünün ailesinin sosyoekonomik durumunun orta seviyede olduğu saptanmıştır. Anne ve babalarından en az birinin eğitim seviyesi lise ve üstü olan öğrencilerin oranı ise \%21,2'dir.

Çalışmaya dahil edilen öğrencilerin \%88,3’ü üç ana öğün , \%62,3 öğrenci ise üç ana öğün yanında günde bir veya iki kez ara öğün tüketmektedir.

Ana ve ara öğün sayısının DMFT ve dmft skorları üzerinde anlamlı bir etkisi görülmemiştir $(\mathrm{p}>0,05)$.

Öğrencilerin \%79'u diş hekimine hiç gitmemiştir. \%21'i ise en az bir kez diş hekimine başvurmuştur. Öğrencilerin \%22'si dişlerini hiç fırçalamazken \%78' inin günde en az bir kez dişlerini fırçaladığı, bunlarında \%94’ünün musluk suyu ile dişlerini fırçaladıkları saptanmıştır.
Yaşa göre düzenli diş fırçalama alışkanlıkları değerlendirildiğinde öğrenciler yaşla birlikte diş fırçalama oranının arttığı görülmüştür $(\mathrm{p}<0,05)$. Ancak düzenli diş fırçaladıklarını belirten öğrencilerle, diş fırçalama alışkanlıklarının olmadığını belirten öğrenciler arasında toplam çürük diş sayısı yönünden istatistiksel olarak anlamlı bir farklılık saptanmamıştır ( $\mathrm{p}>0,05)$.

Araştırmaya dahil olan 4 ile 15 yaş arası 2358 çocuktan, diş çürüğü sorunu olan çocuklardaki toplam diş çürüğü sayısı 8755’tir. Özellikle karışık dişleme dönemine ait total veri analizlerinde DMFT indeksleri bireysel durumu tam yansıtmayabilir. Bu durumda kişi başına düşen çürük oranı önem kazanmaktadır. Çalışmaya ait tüm veriler analizi yapıldığında kişi başına düşen çürük oranı 3,7 olarak tespit edilmiştir. 4 ila15 yaş arası çalışmaya dahil edilen tüm çocuklardan 2218’inde diş çürüğü mevcuttur (Tablo2). 
Tablo 2. Araştırma kapsamında muayene edilen öğrencilerin diş fırçalama alışkanlıkları ve diş çürüğü durumunu yansıtan verilerin dağılımı

\begin{tabular}{|c|c|c|c|c|c|c|c|}
\hline Yaş & $\begin{array}{c}\text { Toplam } \\
\text { kişi }\end{array}$ & $\begin{array}{c}\text { Diş } \\
\text { fırçalama } \\
(-)\end{array}$ & $\begin{array}{c}\text { Diş } \\
\text { fırçalama } \\
(+)\end{array}$ & $\begin{array}{c}\text { Çürüğü olan } \\
\text { kişi sayısı }\end{array}$ & $\begin{array}{c}\text { Çürük diş } \\
\text { sayısı toplamı }\end{array}$ & $\begin{array}{c}\text { Ortalama } \\
\text { dmft }\end{array}$ & $\begin{array}{c}\text { Toplam kişi } \\
\text { sayısı (\%) }\end{array}$ \\
\hline 4 & 8 & 8 & 0 & 3 & 12 & 1,5 & $8(0,3)$ \\
\hline 5 & 26 & 24 & 2 & 21 & 80 & 3,07 & $26(1,1)$ \\
\hline 6 & 68 & 39 & 28 & 59 & 324 & 4,76 & $68(2,8)$ \\
\hline 7 & 310 & 146 & 164 & 273 & 1493 & 4,81 & $310(13,1)$ \\
\hline 8 & 212 & 50 & 162 & 196 & 1138 & 5,37 & $212(8,9)$ \\
\hline 9 & 237 & 85 & 152 & 215 & 1156 & 4,88 & $237(10)$ \\
\hline 10 & 288 & 93 & 195 & 266 & 1197 & 4,16 & $288(12,2)$ \\
\hline 11 & 295 & 86 & 209 & 242 & 933 & 3,16 & $295(12,5)$ \\
\hline 12 & 323 & 107 & 216 & 256 & 915 & 2,83 & $323(13,6)$ \\
\hline 13 & 290 & 91 & 199 & 221 & 735 & 2,53 & $290(12,2)$ \\
\hline 14 & 267 & 81 & 186 & 207 & 686 & 2,57 & $267(11,3)$ \\
\hline 15 & 34 & 6 & 28 & 29 & 110 & 3,24 & $34(1,4)$ \\
\hline & & & & & & $2358(100)$ \\
\hline
\end{tabular}

Tablo 3. Dünya Sağlık Örgütü'nce önerilen yaş gruplarının diş çürüğü prevalans hızı, DMFT/dmft dağılımı

\begin{tabular}{|c|c|c|c|c|c|}
\hline Yaş & Diş Çürüğü Prevalans Hızı & $\begin{array}{c}\text { DMFT/ } \\
\text { Dmft }\end{array}$ & $\begin{array}{l}\text { Erkek } \\
\text { Çocuk }\end{array}$ & Kız Çocuk & Toplam Kişi \\
\hline \multirow{4}{*}{5} & \multirow{4}{*}{80,7} & & $n=13$ & $\mathrm{n}=13$ & $\mathrm{n}=26$ \\
\hline & & $\mathrm{O}$ & $\% 23,1$ & $\% 15,4$ & $\% 19,2$ \\
\hline & & $(1-6)$ & $\% 60,2$ & $\% 53,8$ & $\% 61,6$ \\
\hline & & $(7,+)$ & $\% 7,7$ & $\% 30,8$ & $\% 19,2$ \\
\hline \multirow{4}{*}{12} & \multirow{4}{*}{79,5} & & $n=139$ & $n=134$ & $n=273$ \\
\hline & & $\mathrm{O}$ & $\% 5$ & $\% 6,7$ & $\% 5,9$ \\
\hline & & $(1-6)$ & $\% 82,8$ & $\% 85,1$ & $\% 83,8$ \\
\hline & & $(7,+)$ & $\% 12,2$ & $\% 8,2$ & $\% 10,3$ \\
\hline \multirow{4}{*}{15} & \multirow{4}{*}{85,2} & & $\mathrm{n}=15$ & $\mathrm{n}=13$ & $\mathrm{n}=28$ \\
\hline & & $\mathrm{O}$ & $\% 0$ & $\% 0$ & $\% 0$ \\
\hline & & $(1-6)$ & $\% 100$ & $\% 84,6$ & $\% 92,8$ \\
\hline & & $(7,+)$ & $\% 0$ & $\% 15,4$ & $\% 7,2$ \\
\hline
\end{tabular}

- Genel olarak toplumun ağız ve diş sağlığı düzeyinin belirlenmesinde DSÖ çocuklar için 5 yaş, 12 yaş ve 15 yaş gruplarının önemle değerlendirilmesini ifade etmektedir. DMFT [çürük (Decayed), kayıp (Missing) ve dolgulu (Filled)] indeksi hesaplanırken, DSÖ tarafından 30 yaşın altındaki kişiler için kayıp diş sayısı olarak yalnız “eksik, çürük nedeniyle” kodu almış dişlerin hesaplamaya katılması önerilmektedir. Çalışmaya ait veri analizlerinde bu öneriler dikkate değer olup bu yöndeki veriler Tablo 3 'de verilmektedir.
Diș çürüğü prevalans hızı yönünden 5 yaş, 12 yaş, 15 yaş grupları arasında anlamlı farklılık tespit edilmemiştir. Yaş grupları kendi içinde değerlendirildiğinde her üç yaş gurubunda da, $(7,+)$ çürük dişi olan kişi sayısı açısından erkek çocuklar ile kız çocuklar arasında istatistiksel anlamlı farklılığın olduğu $(\mathrm{p}<0,05)$ tespit edilmiştir. Çalışmaya dahil edilen 1801 öğrenciye koruyucu ve tedavi edici tıbbi uygulamalar dahilinde yerel flor uygulaması 440 öğrenciye ise fissür örtülmesi tedavisi yapılmıştır (Şekil 1) 


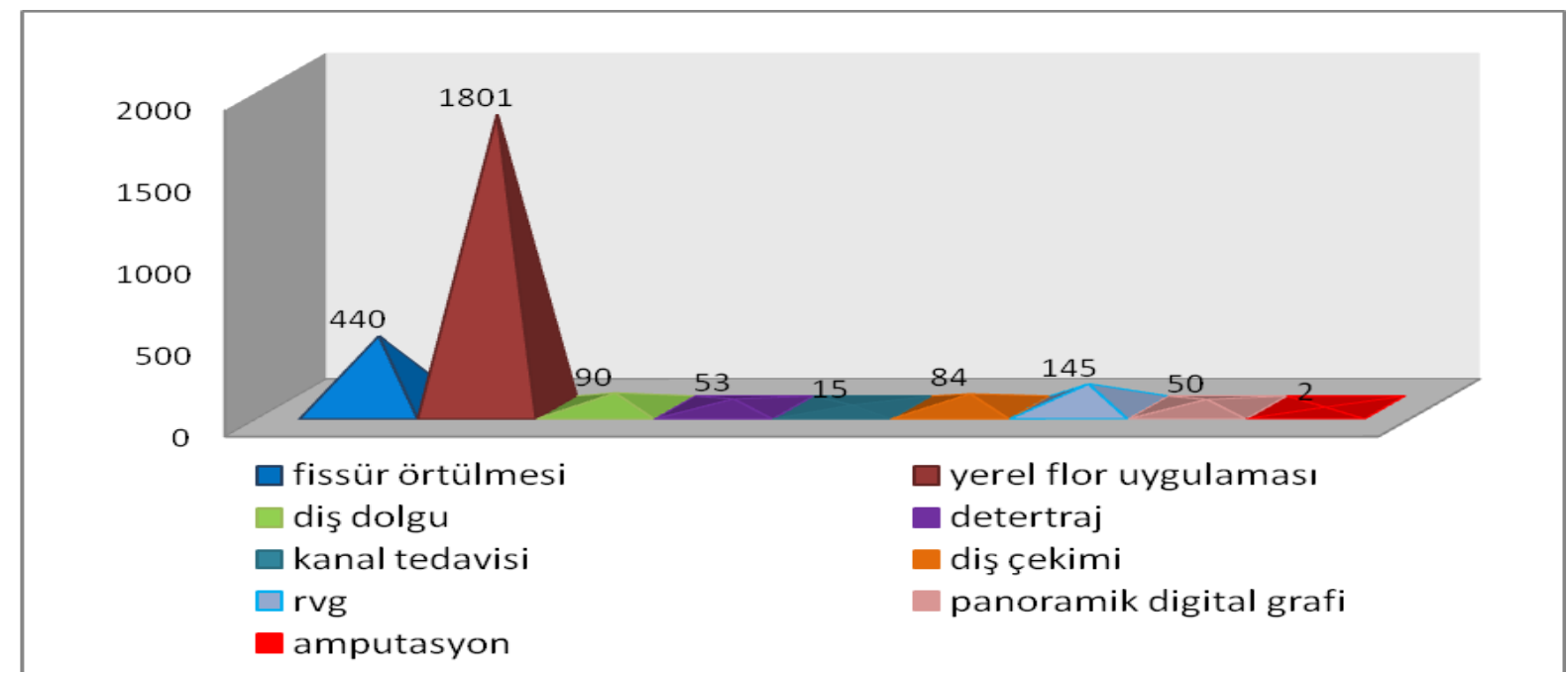

Şekil 1. Araştırma kapsamında muayene edilen kişilerin ağız ve diş sağlığına yönelik risk tespit edilen kişilere yapılan uygulamaların dağılımı

\section{TARTISMA}

Ağız ve diş hastalıkları, sağlık alanındaki gelişmelere rağmen halen sik görülen, tedavi maliyeti yüksek, kronik bir toplumsal sağllk sorunudur. Bu nedenle küçük yaşlardan itibaren bu konuda eğitime başlanmalı ve koruyucu tedbirler alınmalıdır. Ağız ve diş sağlı̆̆ 1 hizmetlerinde koruyucu ve tedavi edici uygulamaların daha etkin ve uygulanabilir olması için öncelikle toplumun ağız ve diş sağlığı profili ile buna etki eden etyolojik faktörlerin belirlenmesi gereklidir (13). Böylece doğru zamanda yapılacak başarılı mudahalelerle, uzun dönemde olumsuz sonuçlar önlenerek bireylerin yaşam kalitesiarttırılabilir.

Bu çalışma, ülkemiz kırsalına ait bir kesit olan, Adıyaman Çelikhan ilçesindeki 26 ilköğretim okulunda öğrenim gören 4 ila 15 yaş arası öğrencilerde, DMFT (Çürük Kayıp-Dolgulu Diş) indeksi kullanılarak diş çürüğü profilini ortaya koyulmuş, örneklemin ağız ve diş sağlı̆ğ durumları ile bunları etkileyen faktörler değerlendirilmiştir.

Araştırmamıza katılan çocukların \%84.3'ünde diş çürüğü saptanmıştır. Yaş gruplarına göre çürük prevalansı, 5 yaş grubunda \%80,7, 12 yaş grubunda \%79,5, 15 yaş grubunda ise $\% 85.2$ olarak bulunmuştur. Ülkemizin farklı bölge ve zamanlarında yapılan benzer çalışmalarda da bizim çalışmamızın sonuçlarına yakın sonuçlar bulunmuştur. Malatya ilinde Güler ve arkadaşları yaptıkları bir çalışmada 7-12 yaş grubu çocuklarda çürük prevalansını \%82,6 olarak saptamış, benzer şekilde Sivas il merkezinde Kambek Taşveren ve arkadaşları tarafından yapılan bir başka çalışmada ise 12 yaş grubu için çürük prevalansı \%79.6 olarak bildirilmiştir $(14,15)$. Yurt dışında yapılan benzer çalışmalara bakıldığında; Hindistan'da 12 yaş grubu çocuklarda çürük prevalansı \%22,3, sosyoekonomik yönden az gelişmiş olmasına rağmen Güney Doğu Asya'nın Laos kentinde ise 12 yaş grubunda çürük prevalansı \%56 olarak tespit edilmiştir $(16,17)$. Bizim çalışmamız ve ülkemizde yapılan diğer çalışmalar da, bazı bölgelerimizde çocuklarda diş çürüğü prevalansının halen yüksek olduğuna işaret etmektedir. Bu nedenle Koruyucu Ağız ve Diş Sağllğı Hizmetlerine verilen önem artırılmalı, özellikle ağız ve diş sağlığı hizmetlerine ulaşmakta güçlük çeken, sosyoekonomik düzeyin düşük olduğu ve dezavantajlı gruplarda yer alan kişilere hizmet verilmesi sağlanmalıdır.

Çalışmamızda öğrencilerin DMTF değerleri yaş gruplarına göre değerlendirildiğinde; 5 yaş grubu DMTF indeksi 3,07, 12 yaş grubu DMTF indeksi 2,83, 15 yaş grubu DMTF indeksi 3,24 olarak saptanmıştır. Yaş grupları arasında DMTF indeksleri açısından istatistiksel olarak anlamlı bir farklılık görülmemiştir. Bu sonuçlar DSÖ’nün 2020 yılına kadar 12 yaş grubu bireylerin ortalama DMFT indeksinin 1,5' ten fazla olmaması hedefine uygun değildir. Ülkemizde yapılan kapsamlı bir saha çalışmasında toplamda 7833 hasta değerlendirilmiş, 12 yaş grubu çocukları DMFT indeksi 1,9; 15 yaş grubu çocukların DMFT indeksi ise 2,3 bulunmuştur (18). Güler ve arkadaşları Malatya'da 7 ila12 yaş grubu çocuklarda DMFT indeks değerini 2,38 $\pm 2,84$ olarak, Kambek Taşveren ve arkadaşları Sivas ilinde 12 yaş grubunda DMFT indeks değeri

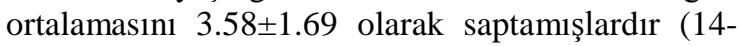
15). Batı bölgemizde yer alan İzmir ilinin Seferihisar ilçesinde yapılan benzer bir çalışmada da, 8 ila 12 yaş grubu çocukların DMFT indeksi 
ortalama 1,01 olarak belirtilmiştir. Ülkemizin farklı bölgelerinde yapılan benzer çalışmaların sonuçlarındaki farklılığın sosyoekonomik seviye ve ağız ve diş sağlığı hizmetlerine ulaşmadaki bölgesel farklılıklardan kaynaklandığını düşünmekteyiz. Yurt dişında yapılan benzer çalışmalarda 12 yaş grubu DMTF indeksi İspanya'da 3,30, Katar da $4.79( \pm 3.2)$ olarak saptanmıştır $(19,20)$. Aynı çalışmada diğer ülkelerdeki aynı yaş grubundaki çocuklarda DMTF indeksi değerleri Hindistan'da 0.86, Nepal'de 1.6, İtalya'da 1.9, Filipinler'de 2.4, Brezilya'da 2,9, Meksika'da 3,1, Peru'da 3,9 olarak belirtilmiştir.

Çalışmamıza dahil olan öğrencilerin \%22’si dișlerini hiç fırçalamazken \%78' inin günde en az bir kez dişlerini fırçaladığı saptanmıştır. Yapılan çalışmalarda diş fırçalama ve ağız bakımı alışkanlığının ağız-diş sağlığını olumlu yönde etkilediği bildirilmiştir (21). Diş fırçalama alışkanlığı toplumlarda farklı dağılımlar göstermektedir. Ülkemizde İsparta ilinde yapılan benzer bir çalışmada 12 ila 16 yaş grubu çocukların \%25’inin dişlerini günde iki kere fırçaladıkları belirtilmiştir (22). Malatya ilinde yapılan bir diğer çalışmada 7 ila 14 yaş grubu çocukların \%31'inin günde en az iki kez dişlerini fırçaladıkları belirtilmiştir(14). 2011 yılında 8 ila 12 yaş grubu 107 çocuk üzerinde yapılan bir başka çalışmada da çocukların \%72,9'unun günde en az 1 kez dişlerini fırçaladıkları saptanmıştır (23). Bu sonuçlar, çocukların diş fırçalama alışkanlığı konusunda yeterince eğitilmediğini göstermektedir.

Çalışmamıza dahil edilen öğrencilerin \%88,3'ü üç ana öğün , \%62,3'ü ise üç ana öğün yanında günde bir veya iki kez ara öğün tüketmektedir. Ana ve ara öğün sayısının DMFT indeks skorları üzerinde anlamlı bir etkisi görülmemiştir ( $p>0,05)$. Yurt dişında yapılan bir çalışmada çocuklarda düzenli ana öğün tüketiminin ara öğünlerde şekerli gıda alımınını azaltarak diş çürüğü riskini düşürdüğü gösterilmiştir (24). Bizim çalışmamızda da öğrencilerin yüksek oranda üç ana öğün tükettikleri ve bunun ara öğünlerde şekerli gıda alımını azalttığıgörülmüştür.

Çalışmamızda öğrencilerin \%89,4’ünün ailesinin sosyoekonomik durumunun orta seviyede olduğu saptanmıştır. Anne ve babalarından en az birinin eğitim seviyesi lise ve üstü olan öğrencilerin oranı ise \%21,2'dir. Anne ve babaların eğitim ve sosyoekonomik durumlarının ağız-diş sağlığını etkilediği bilinmektedir (25,26).Yapilan çalışmalarda sosyoekonomik açıdan düşük seviyede olan ailelerin çocuklarının diş bakımlarını ihmal ettiği tespit edilmiştir (27). Benzer çalışmalarda çocuklardaki ağı bakımı alışkanlıklarının ebeveynlerin eğitim düzeyi ve davranışlarıyla birebir ilişkili olduğu öne sürülmüştür (28-30). Bizim çalışmamızda da tüm yaş gruplarında DMTF indeks skorları ile anne ve babaların eğitim seviyeleri ve sosyoekonomik düzeyleri arasında istatistiksel olarak anlamlı bir farklılıkbulunmadı.

\section{SONUÇ VE ÖNERİLER}

Koruyucu ağız ve diş sağlığına erken önlem alınması açısından tedavi edici sağlık hizmetlerinin okul sağlığı hizmetlerinin bir parçası şeklinde planlanması, yapılan sağlık harcamalarından daha verimli sonuçların alınmasını sağlar. Etkin bir şekilde kayıt altına alınarak yapılan tarama muayeneleri neticesinde yüksek riskli çocuklarda dahi diş hastalığı riski azalmış olmasının yanında ,erken müdahaleler ile maliyetler de düşürülecektir. Sürdürebilirlik ilkesine uygun verilmesi gereken bu hizmetler devamlılık arz ederse Dünya Sağlık Örgütü (DSÖ) nun tanımına uygun sağlıklı toplum ve gelecek hedefine ulaşmak için önemli adımlardan biri atılmış olur $(31,32)$.

\section{KAYNAKLAR}

1. Öztunç H, Haytaç MC, Özmeriç N, et al. Adana ilinde 6-11 yaş grubu çocukların ağız diş sağlığı durumlarının değerlendirilmesi (Adana DSİ İlköğretim Okulu, 1999). GÜ Diş Hek Fak Derg 2000; 17:1-6.

2. Gökalp S, Guciz Doğan B, Tekçiçek M, et al. National survey of oral health status of children and adults in Turkey. Community Dent. Health. 2010: 27(1); 12-17

3.Yabao RN, Duante CA, Velandria FV, et al. Prevalence of dental caries and sugar consumption among 6-12 y-old schoolchildren in La Trinidad, Benguet, Philippines. Eur J Clin Nutr 2005; 59: 1429-38

4. Topaloğlu-Ak A, Eden E, Frencken JE. Managing dental caries in children in Turkey - a discussion paper. BMC Oral Health 2009,9:32.

5.Cengiz, T. Endodonti. 4. Baskı, İzmir; Barış Yayınları 1996; 89-162

6. Llena C, Forner L. Diatery habits in a child population to caries experience. Caries Res 2008; 42:387-93

7. Naidoo S, Myburgh N. Nutrition, oral health and the young child. Matern Child Nutr 2007; 3:312-21.

8. Casamassimo PS, Thikkurissy S, Edelstein BL, et al.(2009) Beyond the dmft: the human and economic cost of early childhood caries. J Am Dent Assoc. , Vol.140, No 6, Jun, pp. 650-7

9. Kawashita,Kitamura M, Saito T. (2011) Early childhood caries. Int J Dent., Vol. 2011, Oct. pp. 725320.

10. Broadbent JM, Thomson WM, Boyens JV,et al. Dental plaque and oral health during the first 32 years of the life. J Am Dent Assoc 2011;142: 415- 26.

11.Bayar B. Diş hekimliği öğrencilerinde diş çürükleri risk profili ve koruyucu uygulamalarla ilgili bilgi ve tutumları. İ.Ü. Diş Hekimliği Fakültesi Bitirme Tezi 2005.

12. WHO. Oral Health Surveys-Basic Methods. 4th Edition. World Health Organization, Geneva 1997

13. Torrence ME. Understanding Epidemiology. Mosby’s Biomedical Science Seriess. Missouri, MosbyYear Book Inc., 1997. 
14. Güler Ç, Eltas A, Güneş D, et al. Malatya İlindeki 7-14 Yaş Arası Çocukların Ağız-Diş Sağlığının Değerlendirilmesi. İÜ Sağ Bil Derg. 2012;2:19-24.

15. Kambek Taşveren S, Yalçın Yeler S, Sözen A, et al. 12 yaş grubu çocuklarda diş fırçalama sıklığı ve DMFT İlişkisi. Atatürk Üniv. Diş Hek. Fak. Dergisi. 2005;15(3):11-4.

16. Saravanan S, Anuradha KP, Bhaskar DJ. Prevalence of dental caries and treatment needs among school going children of Pondicherry, India. Journal of Indian Society of Pedodontics and Preventive Dentistry. 2003;21(1):1-12.

17. Jürgensen AN, Petersen PE. Oral health and the impact of sociobehavioural factors in a cross sectional survey of 12-year old

18. Gökalp SG, Doğan BG, Tekçiçek MT, et al. National survey of oral health status of children and adults in Turkey. Community Dent Health. 2010; 27:12-7.

19. Alvarez-Arenal A, Alvarez-Riesgo JA, Peña-Lopez JM,et al. DMFT, dmft and treatment requirements of school children in Asturias, Spain. Community Dent Oral Epidemiol. 1998;26(3):166-9.

20. Al-Darwish M, El Ansari W, Bener A. Prevalence of dental caries among 12-14 year old children in Qatar. The Saudi Dental Journal. 2014;26:115- 25.

21. Carvalho JC, Van Nieuwenhuysen JP, D'hore W. The decline in dental caries among Belgien children between 1983 and 1998. Community Dent Oral Epidemiol. 2001;29(1):55- 61.

22. Bozkurt FY, Kıran M. Yetiştirme yurdunda kalan 12- 16 yaş grubu bireylerde ağız sağlığı bulguları. Cumhuriyet Üniversitesi Dişhekimliği Fakültesi Dergisi 2005; 8:31-7.

23. Yıldırım M, Bayram M, Patır A, et al. 8-12 Yaş arası çocuklarda görülen kötü ağız alışkanlıklarının sıklığı. İstanbul Üniversitesi Dişhekimliği Fakültesi Dergisi 2011; 45:29-40

24. Bruno-Ambrosius K, Swanholm G, Twetman S. Eating habits, smoking and toothbrushing in relation to dental caries: a 3-year study in Swedish female teenagers. Int J Paediatr Dent. 2005; 15:190-6.

25. Petti S. Why guidelines for early childhood caries prevention could be ineffective amongst children at high risk. J Dent. 2010;38(12):946-55.

26. Burt BA. Fluoridation and social equity. J Public Health Dent. 2002;62(4):195-200.

27. Tulunoğlu Ö, Bodur H, Ulusu T, et al. Okul öncesi (3-6 yaş) ve okul çağındaki (7-12 yaş) çocuklarda diş yüzeylerindeki çürük dağılımının ve prevalansının karşılaştırmalı olarak değerlendirilmesi. GÜ Diş Hek Fak Derg 2003; 20:11-6.

28. Ayele FA, Taye WB, Ayele TA, et al. Predictors of dental caries among children 7-14 years old in Northwest Ethiopia: a community based cross-sectional study. BMC Oral Health 2013; 13:7.

29. Chu CH, Fung DSH, Lo ECM. Dental caries status of preschool children in Hong Kong. British Dental Journal, 1999; 187:616-20.

30. Petersen PE. Oral health behavior of 6 years old Danish children. Acta Odont Scand 1992; 50:57- 64.

31. Davies GM, Duxbury JT, Boothman NJ, et al.(2007), Challenges associated with the evaluation of a dental health promotion programme in a deprived urban area. Community Dent. Health, Vol.24 ,No 2, Jun, pp.117-21

32. Kressin NR, Nunn ME, Singh H, et al. Pediatric clinicians can help reduce rates of early childhood caries: effects of a practice based intervention. Med Care. 2009; 47(11): 1121 